\title{
FERTILIZANTE FOLIAR EM FEIJOEIRO DE INVERNO E SUA INFLUÊNCIA NA PRODUTIVIDADE E QUALIDADE FISIOLÓGICA DAS SEMENTES
}

\section{ÍTALO BAZZO DE OLIVEIRA ${ }^{1}$, GABRIEL WANDERLEY DE MENDONÇA ${ }^{1}$, FLÁVIO FERREIRA DA SILVA BINOTTI ${ }^{1}$, ALEXANDRE DE ARAÚJO ASCOLI', EDILSON COSTA ${ }^{1}$}

Universidade Estadual de Mato Grosso do Sul, Unidade Universitária de Cassilândia-MS, Brasil,
italo_baz@zohotmail.com; gabrielwym@hotmail.com; binotti@uems.br; aaascoli@yahoo.com.br, mestrine@uems.br

RESUMO: Aplicação de nutrientes via foliar pode propiciar efeito direto no crescimento do feijoeiro e consequentemente na produtividade e qualidade das sementes. O objetivo foi avaliar nas cultivares BRS pontal e pérola a resposta da aplicação de nutrientes via foliar no crescimento, na produtividade do feijoeiro, além da qualidade fisiológica das sementes produzidas nesses tratamentos. $\mathrm{O}$ experimento foi realizado a campo da área experimental da Unidade Universitária de Cassilândia/Universidade Estadual de Mato Grosso do Sul. O delineamento experimental utilizado foi o de blocos casualizados em esquema fatorial $2 \times 4$, constituído por cultivares (BRS Pontal e Pérola) e aplicação de fertilizantes via foliar (Testemunha, Adubo foliar 1, Adubo foliar 2 e Adubo foliar 1 + Adubo foliar 2) no estádio $\mathrm{V}_{4}$, com quatro repetições. Foram avaliadas as características: população de plantas, fitomassa, componentes de rendimento, produtividade e qualidade fisiológica das sementes. A cultivar BRS Pontal obteve maior produtividade e qualidade fisiológica de sementes em relação a cultivar Pérola. A adubação foliar não influenciou a produtividade, todavia propiciou sementes com maior velocidade de germinação.

PALAVRAS-CHAVE: Phaseolus vulgaris, cultivares, nutrientes, vigor.

\section{FOLIAR FERTILIZER IN WINTER BEAN AND ITS INFLUENCE ON YIELD AND PHYSIOLOGICAL QUALITY OF SEEDS}

\begin{abstract}
Foliar application of nutrients can provide direct effect on bean growth and consequently on seed yield and quality. The objective was to evaluate the responses of cultivars BRS Pontal and Perola to foliar application of nutrients on bean growth and yield, in addition to seed quality produced in these treatments. The experiment was carried out at the experimental area of the Mato Grosso do Sul State University, in Cassilândia-MS, Brazil. The experimental design was randomized blocks in a $2 \times 4$ factorial design, consisting of two cultivars (BRS Pontal and Perola) and foliar application of nutrients (control, foliar fertilizer 1, foliar fertilizer 2 and foliar fertilizer $1+$ foliar fertilizer 2) at V4 stage, with four replications. The plant population, dry biomass, yield components, grain yield and physiological seed quality were measured. Cultivar BRS Pontal had the highest grain yield and physiological quality of seeds compared the cultivar BRS Perola. The foliar fertilization did not affect grain yield; however, resulted in seeds with higher germination speed.
\end{abstract}

KEYWORDS: Phaseolus vulgaris, cultivars, nutrients, vigor. 


\section{INTRODUÇÃO}

O feijoeiro é cultivado em praticamente todos os estados brasileiros, nas mais variadas condições edafoclimáticas e em diferentes épocas e sistemas de cultivo, tanto em culturas de subsistência, quanto em cultivos altamente tecnificados, sendo que o Paraná ocupa a primeira colocação. A preferência da população brasileira por determinados tipos de grãos é regionalizada. Enquanto o feijão preto é consumindo principalmente no estado de Minas Gerais, a demanda pelo feijão carioca, atualmente o mais consumido no Brasil, é maior nos estados do Rio de Janeiro, Santa Catarina e Rio Grande do Sul (BORÉM; CARNEIRO, 2006). Estima-se que apenas $10 \%$ da área cultivada com feijão no Brasil utiliza sementes selecionadas. Difícil acreditar que um insumo básico como a semente tenha chegado a um nível tão baixo de prioridade, quando se deseja produzir sustentavelmente (COBUCCI et al., 2010).

A produção, distribuição e comercialização de sementes são de estrema importância e o êxito destas atividades depende de um perfeito relacionamento entre as equipes de melhoramento e os técnicos responsáveis pela produção de sementes. A semente é um pacote de energia cuidadosamente elaborado para a função de produzir uma nova planta, e da sua origem derivam os resultados da nova safra. Inúmeras pesquisas são desenvolvidas no sentido de se alcançar sementes com melhorias em seu potencial fisiológico; muitas destas pesquisas são direcionadas aos efeitos da aplicação de diferentes nutrientes na produção de sementes. A disponibilidade de nutrientes influencia a formação do embrião e dos cotilédones com resultados eficazes sobre o vigor e a qualidade fisiológica. No entanto, há poucos trabalhos que relacionam a adubação e nutrição das plantas produtoras de sementes com sua qualidade fisiológica, em relação à aplicação de micronutrientes as pesquisas são ainda mais escassas. (TEIXEIRA et al., 2005).

O cultivo de feijão irrigado ocorre no período de outono-inverno, nas regiões sudeste, centro-oeste e parte do nordeste do Brasil. Os rendimentos geralmente são superiores a 1500 $\mathrm{kg} \mathrm{ha}^{-1}$, bem maiores que os obtidos sem irrigação nas outras épocas de semeadura. Esses rendimentos são tanto elevados quanto mais apropriada é a tecnologia utilizada pelos produtores, podendo ultrapassar $3000 \mathrm{~kg} \mathrm{ha}^{-1}$ (VIEIRA; RAVA, 2000).

A área de feijão segunda safra, ano de 2013, indica que foram semeadas áreas menores em todos os estados produtores, estimando em 1,27 milhão de hectares, o que configura um decréscimo de 8,8\% em relação à safra passada. As áreas que apresentaram tais reduções nesta safra estão basicamente no Nordeste e nas áreas da Região Centro-Sul. Apesar da comercialização instável e dos riscos climáticos adversos à cultura do feijão ainda pode se tornar rentável uma oportunidade para os produtores investirem nesta cultura na Região Centro-Sul (CONAB, 2013) pode se tornar rentável.

Em experimento avaliando aplicação de quatro doses de Molibdênio (0, 40, 80 e $160 \mathrm{~g}$ $\mathrm{ha}^{-1}$ ) e duas épocas de aplicação (15 ou 26 Dias Após Emergência - DAE), tendo como fonte o molibdato de amônio (54\% de Mo), Ascoli et al. (2008) verificaram que a aplicação de Mo via foliar aumentou a produtividade de sementes e a fitomassa seca da parte aérea de plântulas do feijoeiro irrigado, cultivado em solo arenoso, independentemente da época de aplicação (15 ou 26 DAE). A aplicação de Mo aos 26 DAE aumentou a porcentagem de germinação das sementes do feijoeiro.

Em trabalho avaliando cinco doses de Nitrogênio (25;50;75; 100 e $125 \mathrm{~kg} \mathrm{ha}^{-1}$ ), associados com e sem a aplicação foliar de $80 \mathrm{~g} \mathrm{ha}^{-1}$ de Mo, Calonego et al. (2010) verificaram que a ausência de suplementação de Mo via adubação foliar promoveu o acúmulo de nitrato na folha à medida que aumentou a quantidade de $\mathrm{N}$ fornecida, evidenciando a baixa eficiência na assimilação de $\mathrm{N}$ na falta desse micronutriente. Entre os componentes de 
produção do feijoeiro, a massa de cem grãos respondeu positivamente à suplementação de Mo via adubação foliar, proporcionando maior massa de cem grãos com menor dose de $\mathrm{N}$ em cobertura. A adubação molíbdica aumentou a produtividade do feijoeiro independentemente da dose de $\mathrm{N}$ aplicada em cobertura.

Informações sobre a influência da aplicação de fertilizantes via foliar sobre a produtividade e qualidade de sementes de feijão são muito escassas, portanto, há uma grande necessidade de pesquisas sobre o assunto. Diante do exposto, neste trabalho objetivou-se avaliar em cada cultivar de feijão, a resposta da aplicação de nutrientes via foliar, quanto ao crescimento, a produtividade, e a qualidade de sementes.

\section{MATERIAL E MÉTODOS}

O experimento foi realizado na área experimental da Universidade Estadual de Mato Grosso do Sul (UEMS), na Unidade Universitária de Cassilândia (UUC), localizada no município de Cassilândia - MS. O solo do local é classificado como Neossolo Quartzarênico, pela nomenclatura do Sistema Brasileiro de Classificação de Solos (EMBRAPA/CNPSO, 2006).

Para realização da análise química do solo, realizou-se a coleta de amostras de solo na profundidade de 0-0,20 m na área experimental, segundo metodologia descrita por Raij et al. (2001). Na análise química de solo foram determinados os seguintes valores:

Tabela 1 - Características químicas do solo na camada de 0-0,20m, Cassilândia-MS, 2012.

\begin{tabular}{ccccccccccc}
\hline $\begin{array}{c}\mathrm{P}_{\text {resina }} \\
\mathrm{mg} \mathrm{dm}^{-3}\end{array}$ & $\begin{array}{c}\mathrm{M} . \mathrm{O} . \\
\mathrm{g} \mathrm{dm}^{-3}\end{array}$ & $\begin{array}{c}\mathrm{pH} \\
\mathrm{CaCl}_{2}\end{array}$ & $\mathrm{~K}$ & $\mathrm{Ca}$ & $\mathrm{Mg}$ & $\mathrm{H}+\mathrm{Al}$ & $\mathrm{CTC}$ & $\mathrm{SB}$ & $\mathrm{Al}$ & \multirow{2}{*}{$\mathrm{V} \%$} \\
\cline { 6 - 9 } $\mathrm{cmol}_{\mathrm{c}} \mathrm{dm}^{-3}$ & & & \\
\hline $\mathrm{ns}$ & 16,3 & 4,8 & 0,13 & 1,6 & 0,7 & 2,7 & 5,1 & 47,4 & 0,1 & 47,4 \\
\hline
\end{tabular}

Realizou-se no dia 30 de março de 2012 a aplicação de $2.500 \mathrm{~kg} \mathrm{ha}^{-1}$ de calcário para correção de solo de acordo com a análise de solo, com dois meses e meio de antecedência da semeadura do feijão.

O delineamento experimental utilizado foi o de blocos casualizados em esquema fatorial $2 \times 4$ constituído por cultivares (BRS Pontal e Pérola) e aplicação de nutrientes foliares [testemunha (sem aplicação), Adubo foliar 1 (286 ha $\mathrm{ga}^{-1}$ de nitrogênio, $26 \mathrm{~g} \mathrm{ha}^{-1}$ de óxido de potássio e $156 \mathrm{~g} \mathrm{ha}^{-1}$ de carbono orgânico), Adubo foliar $2\left(52,5 \mathrm{~g} \mathrm{ha}^{-1}\right.$ de nitrogênio, $15 \mathrm{~g} \mathrm{ha}^{-1}$ de boro, 6,25 $\mathrm{g} \mathrm{ha}^{-1}$ de cobre, 62,5 $\mathrm{g}^{-1} \mathrm{a}^{-1}$ de manganês, $10,5 \mathrm{~g} \mathrm{ha}^{-1}$ de molibdênio, 52,5 $\mathrm{g} \mathrm{ha}^{-1}$ de zinco e 37,5 $\mathrm{g} \mathrm{ha}^{-1}$ de carbono orgânico) e Adubo foliar 1 + Adubo foliar 2] no estádio $\mathrm{V}_{4}$, com quatro repetições. As parcelas foram constituídas por 4 linhas de 6 metros de comprimento, sendo a área útil para avaliação formada pelas 2 linhas centrais, desprezando meio metro em cada extremidade. A área do experimento foi de $288 \mathrm{~m}^{2}$, sendo constituído por 24 parcelas.

O feijão foi semeado manualmente em 16 de junho de 2012, com uma densidade de semeadura de 16 sementes por metro linear e espaçamento de $0,5 \mathrm{~m}$ entre linhas; sementes suficientes para obtenção de 10 plantas viáveis por metro, após desbaste. As sementes receberam tratamento com fungicida - benomyl (100g do i.a. por $100 \mathrm{~kg}$ de sementes). Após, a semeadura, a área foi irrigada através do sistema de irrigação por aspersão, para promover a germinação das sementes, sendo que, no decorrer do manejo da cultura foi mantida a lâmina de irrigação de acordo com a exigência de água do feijoeiro. 
A adubação química básica no sulco de semeadura foi realizada conforme recomendações de Lobato e Souza (2004), sendo constituída de $20 \mathrm{~kg} \mathrm{ha}^{-1}$ de nitrogênio na forma de ureia, $60 \mathrm{~kg} \mathrm{ha}^{-1}$ de $\mathrm{P}_{2} \mathrm{O}_{5}$ na forma de superfosfato simples e $60 \mathrm{~kg} \mathrm{ha}^{-1}$ de $\mathrm{K}_{2} \mathrm{O}$ na forma de cloreto de potássio (LOBATO; SOUSA, 2004)

Realizou-se no estádio $\mathrm{V}_{3}$, a adubação nitrogenada de cobertura, com $40 \mathrm{~kg} \mathrm{ha}^{-1}$ de nitrogênio na forma de ureia. Após a aplicação de nitrogênio a área foi irrigada com o objetivo de minimizar as perdas de nitrogênio por volatilização.

O controle e a prevenção das principais pragas e doenças na cultura foram realizados por meio de pulverizações com produtos recomendados para a cultura. $\mathrm{O}$ controle de plantas daninhas, quando necessário, foi realizado por meio de capina manualmente. Os demais tratos culturais e fitossanitários foram os normalmente recomendados à cultura do feijão para a região.

O florescimento e a colheita do feijoeiro ocorreram aos 55 e 106 dias, respectivamente, após a semeadura. Realizou-se o controle da temperatura, umidade relativa do ar e precipitação durante o ano de 2012. No Gráfico 1 estão apresentados a temperatura média, umidade relativa do ar e precipitação do ano de 2012.

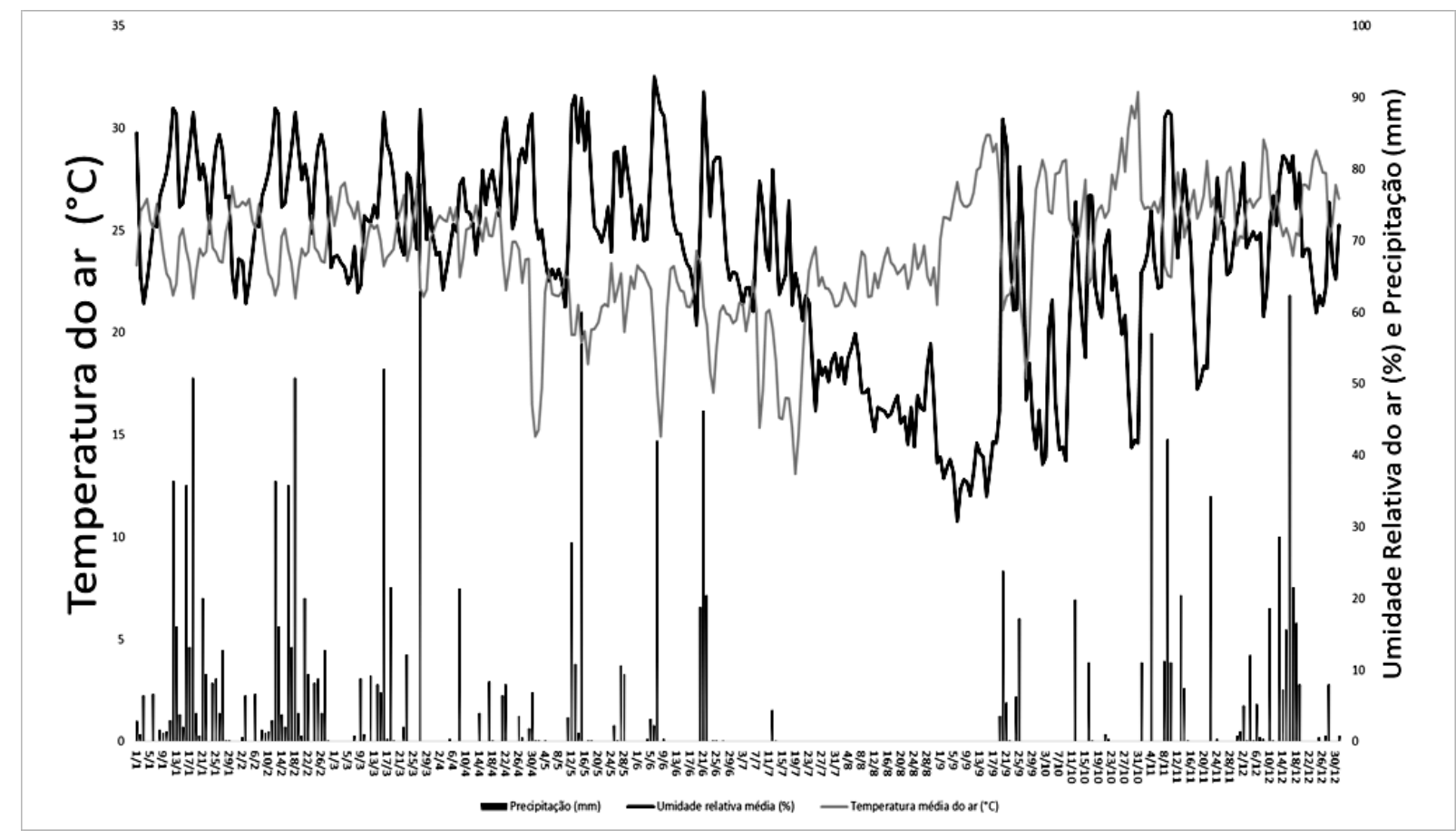

Gráfico 1. Média mensal da Temperatura do ar $\left({ }^{\circ} \mathrm{C}\right)$, Umidade Relativa do ar (\%) e Precipitação (mm) do ano de 2012 da Universidade Estadual de Mato Grosso do Sul (UEMS) na Unidade Universitária de Cassilândia (UUC) no município de Cassilândia - MS.

\section{Avaliações realizadas:}

\section{A) Crescimento e produtividade}

População de plantas inicial e final - Determinou-se a população de plantas por meio da contagem de plantas em duas linhas de cinco metros da área útil das parcelas: população de plantas inicial - realizada na fase $\mathrm{V}_{2}(50 \%$ das plantas com folhas primárias expandidas) e população de plantas final - realizada no momento de colheita. Os dados foram transformados em plantas ha ${ }^{-1}$. 
Fitomassa seca e fresca de planta - Por ocasião do florescimento pleno, foram coletadas 10 plantas em local pré-determinado na área útil e levadas ao laboratório onde foi mensurada a fitomassa fresca. Posteriormente as plantas foram submetidas à secagem em estufa de circulação forçada de ar à temperatura média de $65^{\circ} \mathrm{C}$ até atingir a massa constante. Após, a secagem, foi determinada a fitomassa seca, os valores de fitomassa fresca e seca foram convertidos em $g$ planta $^{-1}$.

Componentes de produção - Foram coletadas 10 plantas em local pré-determinado na área útil de cada parcela e levadas para o laboratório para determinação de: número de vagens por planta, número de sementes por planta, número de sementes por vagem e massa de 100 sementes.

Produtividade - As plantas de cinco metros da área útil de cada parcela foram arrancadas e deixadas para secagem a pleno sol. Após, a secagem as mesmas foram submetidas à trilhagem manual e mensurado sua massa, os dados transformados em $\mathrm{kg} \mathrm{ha}^{-1}$ (13\% de base úmida).

Após serem colhidas, as sementes foram levadas ao Laboratório de Análise de Sementes (UEMS/UUC), onde foram armazenadas em câmara seca. Posteriormente as sementes foram submetidas às seguintes avaliações:

\section{B) Qualidade fisiológica das sementes}

Primeira contagem de germinação - Realizada juntamente com o teste de germinação, sendo o registro da porcentagem de plântulas normais verificadas 5 dias após a instalação do teste, conforme recomendações de Brasil (2009).

Teste de germinação - Realizado com 4 sub-amostras de 50 sementes de acordo com os critérios estabelecidos pelas Regras de Análise de Sementes (BRASIL, 2009).

Índice de velocidade de germinação (IVG) - Realizada concomitantemente ao teste de germinação; o índice de velocidade para cada tratamento foi calculado segundo a fórmula proposta por Maguire (1962).

Teste de condutividade elétrica - Para avaliação da condutividade elétrica da solução de embebição de sementes foi utilizado o método "condutividade de massa" ou sistema de copo. O teste foi realizado com quatro subamostras de 50 sementes, sendo cada subamostra (repetições) foi mensurada com precisão de pelo menos duas casas decimais. Posteriormente, cada subamostra foi colocada para embeber em um recipiente contendo $75 \mathrm{~mL}$ de água deionizada (3-5 $\mu \mathrm{S} \mathrm{cm}^{-1}$ de condutividade), e então mantida em uma câmara (germinador) à temperatura de $25{ }^{\circ} \mathrm{C}$ durante 24 horas. Após, este período realizou-se a leitura da condutividade elétrica na solução de embebição com o uso de condutivímetro. Os resultados foram expressos em $\mu \mathrm{S} \mathrm{cm}^{-1} \mathrm{~g}^{-1}$ de sementes conforme recomendações de Vieira e Kryzanowski (1999).

Teste de envelhecimento acelerado: $O$ envelhecimento artificial foi realizado pelo método do gerbox descrito por Marcos Filho (1999). As caixas do tipo "gerbox" foram levadas ao germinador regulado à temperatura de $42^{\circ} \mathrm{C}$ onde permaneceram durante 72 horas. Após, este período as sementes foram semeadas conforme descrição para o teste padrão de germinação indicada por Brasil (2009).

Todos os dados foram avaliados através da análise de variância pelo teste $\mathrm{F}$, havendo significância, aplicou o teste de Tukey a $5 \%$ de probabilidade para o fator adubação foliar (BANZATTO; KRONKA, 2006). Foi utilizado o programa SANEST - Sistema de Análise Estatística para microcomputadores (ZONTA; MACHADO, 1986). 


\section{RESULTADOS E DISCUSSÃO}

A interação entre os fatores pesquisados não foi significativa, assim os mesmos foram apresentados isoladamente.

Os resultados obtidos na avaliação da população inicial e final de plantas, em função da aplicação de adubos foliares na fase $\mathrm{V}_{4}$ e cultivares não apresentaram diferença significativas (Tabela 1), fato que já era previsto para população inicial, pois na época de avaliação a adubação foliar ainda não tinha sido feita. O mesmo foi observado por Soratto et al.(2011) onde a população final de plantas de feijão não foi influenciada pela aplicação de nitrogênio via foliar.

$\mathrm{Na}$ avaliação da fitomassa fresca e seca não houve diferença para os fatores estudados (Tabela 2); talvez consequência da proximidade da época de aplicação do adubo foliar e a coleta das amostras para fitomassa seca.

Tabela 1. População inicial e final de plantas em função da aplicação de adubação foliar na fase $\mathrm{V}_{4}$ em duas variedades de feijoeiro. UEMS/UUC, Cassilândia (MS), 2012.

\begin{tabular}{|c|c|c|}
\hline \multirow{2}{*}{ Tratamentos } & \multicolumn{2}{|c|}{ População } \\
\hline & Inicial & Final \\
\hline & ------------------- & -------------- \\
\hline \multicolumn{3}{|l|}{ Variedade } \\
\hline Pérola & $\mathrm{M}_{219.667 \mathrm{a}}$ & $214.666 \mathrm{a}$ \\
\hline BRS Pontal & $218.333 \mathrm{a}$ & $212.333 \mathrm{a}$ \\
\hline \multicolumn{3}{|l|}{ Adubação Foliar } \\
\hline Testemunha & $213.000 \mathrm{a}$ & $213.333 \mathrm{a}$ \\
\hline Adubo foliar 1 (N, K e C) & $221.000 \mathrm{a}$ & $222.000 \mathrm{a}$ \\
\hline Adubo foliar 2 (N, Bo, Cu, Mn, Mo, Zn e C) & $227.333 \mathrm{a}$ & $214.000 \mathrm{a}$ \\
\hline Adubo foliar $1+$ Adubo foliar 2 & $214.667 \mathrm{a}$ & $204.667 \mathrm{a}$ \\
\hline C.V. $(\%)$ & 11,45 & 13,77 \\
\hline
\end{tabular}

Tabela 2. Fitomassa fresca e seca de plantas em função da aplicação de adubação foliar na fase $\mathrm{V}_{4}$ em duas variedades de feijoeiro. UEMS/UUC, Cassilândia (MS), 2012.

\begin{tabular}{lcc}
\hline \multicolumn{1}{c}{ Tratamentos } & \multicolumn{2}{c}{ Fitomassa } \\
\cline { 2 - 3 } & Fresca & Seca \\
\hline Variedade & M $57,68 \mathrm{a}$ & $8,93 \mathrm{a}$ \\
Pérola & $51,24 \mathrm{a}$ & $8,63 \mathrm{a}$ \\
BRS Pontal & & \\
Adubação Foliar & $58,76 \mathrm{a}$ & $9,55 \mathrm{a}$ \\
Testemunha & $57,49 \mathrm{a}$ & $9,07 \mathrm{a}$ \\
Adubo foliar 1 (N, K e C) & $54,36 \mathrm{a}$ & $8,42 \mathrm{a}$ \\
Adubo foliar 2 (N, Bo, Cu, Mn, Mo, Zn e C) & $47,22 \mathrm{a}$ & $8,09 \mathrm{a}$ \\
Adubo foliar 1 + Adubo foliar 2 & 28,78 & 23,17 \\
\hline \multicolumn{2}{c}{ C.V.(\%) } & \\
Mádias seguidas de letras diferentes nas colunas, dentro de cada fator, diferem estatisticamente entre si pelo teste F á 5\% de \\
probabilidade para o fator variedade e Tukey a 5\% de probabilidade para o fator adubação foliar.
\end{tabular}


Segundo Binotti et al. (2009) a fitomassa seca de planta de feijoeiro também não foi influenciada pelo modo de aplicação e pelas fontes de nitrogênio, constatando efeitos positivos na dosagem de nitrogênio. Porém, Ascoli et al. (2008) ressaltam que a aplicação de doses crescentes de Mo via foliar proporcionaram aumento linear da fitomassa seca da parte aérea de plântulas.

Em relação ao número de sementes e vagens por planta, a variedade BRS pontal apresentou maior número em relação a cultivar pérola e também maior número de sementes por vagem (Tabela 3). De acordo com os resultados de número de sementes por planta os tratamentos adubo foliar 2 e adubo foliar $1+$ adubo foliar 2 propiciaram maior número de sementes por planta. Para o número de vagens por planta o tratamento adubo foliar $1+$ adubo foliar 2 propiciou maior resultado quando comparado com a testemunha e o adubo foliar 1 . Este resultado sendo decorrente talvez da aplicação do adubo foliar 2 isoladamente ou em conjunto com adubo foliar 1 proporcionaram um maior pegamento de flores e menor abortamento de vagens, corroborando maiores valores nestes dois componentes de produção. Contudo, o número de sementes por vagem não apresentou diferença estatisticamente em relação a adubação foliar pois, esta característica é intrínseca ao cultivar (genótipo) utilizado, sofrendo pouca influência das práticas culturais. No trabalho de Ascoli et al. (2008), utilizando 4 dosagens e duas épocas de aplicação de molibdato de amônio, não houve um aumento no número de vagens por planta e de sementes por vagem no feijoeiro. De acordo com Soratto et al. (2011) a aplicação de $\mathrm{N}$ via foliar não alterou o número de vagens por planta do feijoeiro.

Tabela 3. Componentes de rendimento em função da aplicação de adubação foliar na fase $\mathrm{V}_{4}$ em duas variedades de feijoeiro. UEMS/UUC, Cassilândia (MS), 2012.

\begin{tabular}{lccc}
\hline \multicolumn{1}{c}{ Tratamentos } & \multicolumn{2}{c}{ Número por planta } & No \\
& Sementes & Vagens & vagem \\
\hline $\begin{array}{l}\text { Variedade } \\
\text { Pérola }\end{array}$ & $\mathrm{M}_{34,78 \mathrm{~b}}$ & $9,83 \mathrm{~b}$ & $3,29 \mathrm{~b}$ \\
BRS Pontal & $53,45 \mathrm{a}$ & $11,75 \mathrm{a}$ & $4,66 \mathrm{a}$ \\
$\begin{array}{l}\text { Adubação Foliar } \\
\text { Testemunha }\end{array}$ & $32,61 \mathrm{~b}$ & $8,83 \mathrm{~b}$ & $3,53 \mathrm{a}$ \\
Adubo foliar 1 (N, K e C) & $38,30 \mathrm{~b}$ & $8,78 \mathrm{~b}$ & $3,95 \mathrm{a}$ \\
Adubo foliar 2 (N, Bo, Cu, Mn, Mo, Zn & $51,36 \mathrm{a}$ & $11,75 \mathrm{ab}$ & $4,45 \mathrm{a}$ \\
Adubo foliar 1 + Adubo foliar 2 & $54,20 \mathrm{a}$ & $13,80 \mathrm{a}$ & $3,96 \mathrm{a}$ \\
\hline \multicolumn{1}{c}{ C.V.(\%) } & 14,49 & 18,74 & 19,82 \\
\hline
\end{tabular}

${ }^{\mathrm{M}}$ Médias seguidas de letras diferentes nas colunas, dentro de cada fator, diferem estatisticamente entre si pelo teste $\mathrm{F}$ á $5 \%$ de probabilidade para o fator variedade e Tukey a 5\% de probabilidade para o fator adubação foliar.

A massa de 100 sementes da cultivar Pérola foi superior a constatada na cultivar BRS Pontal (Tabela 4). Porém, a BRS pontal apresentou maior produtividade que a cultivar Pérola. Quanto à adubação foliar observou-se que a massa de 100 sementes com aplicação do adubo foliar $1+$ adubo foliar 2 apresentou resultado inferior aos demais tratamentos; a produtividade não foi influenciada pela adubação foliar.

Calonego et al. (2010) verificaram resultados positivos no aumento da produtividade do feijão com a suplementação de molibdênio via foliar, constatando um acréscimo de $245 \mathrm{~kg}$ ha $^{-1}$ no rendimento médio de grãos.

Na Tabela 5 a cultivar BRS Pontal apresentou maiores valores de primeira contagem de germinação, germinação total e IVG em comparação a Pérola. Em relação a adubação foliar, o adubo foliar $1+$ adubo foliar 2 comparado com a testemunha obteve melhor resultado 
no teste de germinação; já no índice de velocidade de germinação, a mesma propiciou maior IVG, independente da adubação foliar. Pode-se observar na Tabela 5, que o tratamento com aplicação de Adubo foliar 1 + Adubo foliar 2 propiciou sementes com menor massa de 100 sementes. Ainda que a massa de sementes exerce influência direta no vigor das sementes, as mesmas obtiveram resultados que indicam alto vigor. A aplicação de nitrogênio e demais micronutrientes, não alteraram a qualidade fisiológica das sementes de feijão de acordo com Ambrosano et al. (1999). Segundo Meira et al. (2005), utilizando também nitrogênio em seu trabalho, não houve efeito significativo entre os tratamentos quanto à germinação, vigor e primeira contagem.

Tabela 4. Massa de 100 sementes e produtividade em função da aplicação de adubação foliar na fase $\mathrm{V}_{4}$ em duas variedades de feijoeiro. UEMS/UUC, Cassilândia (MS), 2012.

\begin{tabular}{lcc}
\hline \multicolumn{1}{c}{ Tratamentos } & Massa de 100 sementes & Produtividade \\
& ------ g------- & \\
\hline Variedade & $\mathrm{M}_{30,31 \mathrm{a}}$ & $2.509 \mathrm{~b}$ \\
Pérola & $25,75 \mathrm{~b}$ & $3.199 \mathrm{a}$ \\
BRS Pontal & & \\
Adubação Foliar & $29,25 \mathrm{a}$ & $2.862 \mathrm{a}$ \\
Testemunha & $28,44 \mathrm{a}$ & $3.003 \mathrm{a}$ \\
Adubo foliar 1 (N, K e C) & $28,26 \mathrm{a}$ & $2.929 \mathrm{a}$ \\
Adubo foliar 2 (N, Bo, Cu, Mn, Mo, Zn & $26,17 \mathrm{~b}$ & $2.621 \mathrm{a}$ \\
Adubo foliar 1 + Adubo foliar 2 & 3,20 & 17,60 \\
\multicolumn{2}{c}{ C.V.(\%) } &
\end{tabular}

Tabela 5. Primeira contagem e germinação total (5 e 9 dias), índice de velocidade de germinação (IVG) e teste de envelhecimento acelerado em função da variedade e adubação foliares. UEMS Cassilândia (MS), 2013

\begin{tabular}{|c|c|c|c|c|}
\hline \multirow{2}{*}{$\begin{array}{l}\text { Tratamentos } \\
\text { Variedade }\end{array}$} & \multicolumn{3}{|c|}{$1^{a}$ Contagem Germinaçãc IVG } & \multirow[t]{2}{*}{$\begin{array}{l}\text { Envelhecimento } \\
------\% \text {------- } \\
\end{array}$} \\
\hline & & & & \\
\hline Pérola & ${ }^{\mathrm{M}} 97 \mathrm{~b}$ & $97 b$ & $9,72 b$ & $95 \mathrm{a}$ \\
\hline BRS Pontal & $99 a$ & $99 a$ & $9,91 \mathrm{a}$ & $96 a$ \\
\hline \multicolumn{5}{|l|}{ Adubação Foliar } \\
\hline Testemunha & $97 \mathrm{a}$ & $97 b$ & $9,70 b$ & $95 \mathrm{a}$ \\
\hline Adubo foliar 1 (N, K e C) & $98 \mathrm{a}$ & $98 \mathrm{ab}$ & $9,80 \mathrm{a}$ & $96 \mathrm{a}$ \\
\hline Adubo foliar 2 (N, Bo, Cu, Mn, Mo, & $98 \mathrm{a}$ & $98 \mathrm{ab}$ & $9,84 \mathrm{a}$ & $95 \mathrm{a}$ \\
\hline Adubo foliar $1+$ Adubo foliar 2 & $99 \mathrm{a}$ & $99 \mathrm{a}$ & $9,93 \mathrm{a}$ & $97 \mathrm{a}$ \\
\hline C.V.(\%) & 1,83 & 1,345 & 1,50 & 3,28 \\
\hline
\end{tabular}

Observou-se na Tabela 6 que na cultivar Pérola o tratamento adubo foliar $1+$ adubo foliar 2, juntamente com a testemunha, proporcionaram menores leituras de condutividade elétrica. Para cultivar BRS Pontal o tratamento adubo foliar $1+$ adubo foliar 2, juntamente com a testemunha, proporcionaram maiores leituras. No tratamento adubo foliar 1 e adubo foliar 2 maiores valores foram obtidos na cultivar Pérola, já para testemunha e adubo foliar 1 + adubo foliar 2 maiores valores foram obtidos na cultivar BRS Pontal. No trabalho de 
Zucareli et al. (2011) os valores de condutividade elétrica aumentaram linearmente com o aumento das doses de $\mathrm{P}$ aplicadas no solo. No teste de condutividade elétrica não se constatou efeito dos tratamentos com aplicação de manganês via foliar, com valor médio de $57,4 \mu \mathrm{S} \mathrm{cm}^{-}$ ${ }^{1} \mathrm{~g}^{-1}$ (FERNANDES, et al., 2007).

Tabela 6. Desdobramento da análise de variância da condutividade elétrica de sementes de feijão em função da variedade e adubação foliares. UEMS Cassilândia (MS), 2013.

\begin{tabular}{lcc}
\hline \multicolumn{1}{c}{ Adubação Foliar } & \multicolumn{2}{c}{ Variedade } \\
\cline { 2 - 3 } & CRS Pontal & Pérola \\
\hline & M $72,50 \mathrm{aA}$ & $50,71 \mathrm{bB}$ \\
Testemunha & $48,60 \mathrm{cB}$ & $65,88 \mathrm{aA}$ \\
Adubo foliar 1 (N, K e C) & $58,30 \mathrm{bB}$ & $66,35 \mathrm{aA}$ \\
Adubo foliar 2 (N, Bo, Cu, Mn, Mo, Zn & $69,10 \mathrm{aA}$ & $50,15 \mathrm{bB}$ \\
Adubo foliar 1 + Adubo foliar 2 & \multicolumn{2}{c}{3,95} \\
\hline \multicolumn{2}{c}{ C.V.(\%) } & \\
\hline${ }^{\mathrm{M}}$ Médias seguidas de letras diferentes minúscula nas colunas, dentro de cada fator adubação foliar e letras diferentes \\
maiúscula nas linhas, dentro de cada fator variedade diferem estatisticamente entre si pelo teste F á 5\% de probabilidade para \\
o fator variedade e Tukey a 5\% de probabilidade para o fator adubação foliar.
\end{tabular}

\section{CONCLUSÕES}

A cultivar BRS Pontal obteve maior produtividade e qualidade fisiológica das sementes em relação a cultivar Pérola.

A adubação foliar não influenciou a produtividade, todavia propiciou sementes com maior velocidade de germinação.

\section{REFERÊNCIAS BIBLIOGRÁFICAS}

AMBROSANO, E. J.; AMBROSANO, G. M. B.; WUTKE, E. B.; BULISANI, E. A.; MARTINS, A. L. M.; SILVEIRA, L. C. P. Efeitos da adubação nitrogenada e com micronutrientes na qualidade de sementes do feijoeiro cultivar IAC carioca. Bragantia, Campinas-SP, v. 58, n. 2, p. 393-399, 1999.

ASCOLI, A. A.; SORATTO, R. P; MARUYAMA, W. I. Aplicação foliar de molibdênio, produtividade e qualidade fisiológica de sementes de feijoeiro irrigado. Bragantia, Campinas-SP, v. 67, n. 2, p. 377-384, 2008.

BANZATTO, D. A.; KRONKA, S. N. Experimentação Agrícola. Jaboticabal-SP: Funep, 4.ed., 2006, 237p.

BINOTTI, F. F. S.; ARF, O.; SÁ, M. E.; BUZETTI, S.; ALVAREZ, A. C. C.; KAMIMURA, K. M. Fontes, doses e modo de aplicação de nitrogênio em feijoeiro no sistema plantio direto. Bragantia, Campinas-SP, v. 68, n. 2, p. 473-481, 2009.

BRASIL/MAPA. MINISTÉRIO DA AGRICULTURA, PECUÁRIA E ABASTECIMENTO. Regras para análise de sementes. Secretaria de Defesa Agropecuária. Brasília-DF: MAPA/ACS, 2009.

BORÉM, A.; CARNEIRO, J. E. S. A CULTURA. IN: VIEIRA, C.; PAULA JÚNIOR, T. J.; BORÉM, A. (Eds.). Feijão. 2 ed. Atual. Viçosa-MG: UFV, 2006, p.13-18. 
BANZATTO, D. A.; KRONKA, S. N. Experimentação Agrícola. Jaboticabal-SP: Funep, 4.ed., 2006, 237p.

CALONEGO, J.C; RAMOS JUNIOR, E. U.; BARBOSA, R. D.; LEITE, G. H. P.; GRASSI FILHO, H. Adubação nitrogenada em cobertura no feijoeiro com suplementação de molibdênio via foliar, Revista Ciência Agronômica, Fortaleza-CE, v. 41, n. 3, p. 334-340, 2010.

COBUCCI, T.; COSTA, J. G. C.; KTULHOCOUSKI, J. Avanços e limitações no manejo do feijoeiro. In: FANCELLI, A. L. Feijão: Tópico de nutrição e adubação, 2 ed. Piracicaba-SP: USP/ESALQ/LPV, 2010. p. 42-65.

CONAB. COMPANHIA NACIONAL DE ABASTECIMENTO. Acompanhamento da Safra Brasileira de Grãos 2012/13 - Nono Levantamento. Junho/2013. Companhia Nacional de Abastecimento. - Brasília: Conab, 2013.

EMBRAPA. EMPRESA BRASILEIRA DE PESQUISA AGROPECUÁRIA. Sistema Brasileiro de Classificação dos Solos. 2.ed. Brasília: Embrapa/CNPSo, 2006. 306p.

FERNANDES, D. S.; SORATTO, R. P.; KULCZYNSKI, S. A.; BISCARO, G. A.; REIS, C. J. Produtividade e qualidade fisiológica de sementes de feijão em consequência da aplicação foliar de manganês. Pesquisa Agropecuária Brasileira, Brasília-DF, v. 42, n. 3, p. 419-426, 2007.

LOBATO, E.; SOUSA, D. M. G. Calagem e adubação para culturas anuais e semiperenes. In: SOUSA, D. M. G.; LOBATO, E. Cerrado: correção do solo e adubação. 2.ed. Brasília-DF: Embrapa Informações Tecnológicas, 2004. p.295-297.

MAGUIRE, J. D. Speed of germination aid in selection and evaluation for seedling and vigour. Crop Science, Madison, v.2, n.2, p.176-177, 1962.

MARCOS FILHO, J. Teste de envelhecimento acelerado. In: KRYZANOWSKI, F. C., VIEIRA, R. D., FRANÇA NETO, J. B. (Ed.). Vigor de sementes: conceitos e testes. Londrina-PR: ABRATES, 1999. cap.3, p.3.1-3.24

MEIRA, F. A.; SÁ, M. E.; BUZETTI, S.; ARF, O. Doses e épocas de aplicação de nitrogênio no feijoeiro irrigado cultivado em plantio direto. Pesquisa Agropecuária Brasileira BrasíliaDF, v. 40, n. 4, p. 383-388, 2005.

RAIJ, B. VAN. ANDRADE, J. C.; CANTARELlA, H.; QUAGGIO, J. A. Análise química para avaliação da fertilidade de solos tropicais. Campinas-SP: Instituto Agronômico, 2001. $284 \mathrm{p}$.

SORATTO, R. P.; FERNANDES, A. M.; SOUZA, E. F. C.; SOUZA-SCHLICK, G. D. Produtividade e qualidade dos grãos de feijão em função da aplicação de nitrogênio em cobertura e via foliar. Revista Brasileira de Ciências do Solo, Viçosa-MG, v. 35, n. 6, p. 2019-2028, 2011.

TEIXEIRA, I. R.; BORÉM, A.; ARAÚJO, G. A. A.; ANDRADE, M. J. B. Teores de nutrientes e qualidade fisiológica de sementes de feijão em resposta à adubação foliar com manganês e zinco. Revista Bragantia, Campinas-SP, v. 64, n. 1, p. 83-88, 2005.

VIERA, R.D.; KRYZANOWSKI, F.C. Teste de condutividade elétrica. In: KRYZANOWSKI, F.C.; VIEIRA, R.D.; FRANÇA NETO, J.B. (Ed.). Vigor de sementes: conceitos e testes. Londrina-PR: ABRATES, 1999. cap.4, p.4.1-4.26. 
VIEIRA, E. H. N.; RAVA, C. A. (edit.). Sementes de feijão: produção e tecnologia, Santo Antônio de Goiás-GO: Embrapa Arroz e Feijão, 2000. 270p.

ZONTA, E.P.; MACHADO, A.A. Sistema de Análise Estatística para microcomputadores - SANEST. Pelotas-RS: UFPel, Instituto de Física e Matemática, 1986. 150p.

ZUCARELI, C.; PRANDO, A. M.; JUNIOR, E. U. R.; NAKAGAWA, J. Fósforo na produtividade e qualidade de sementes de feijão carioca precoce cultivado no período das águas. Revista Ciência Agronômica, Fortaleza-CE, v. 42, n. 1, p. 32-38, 2011. 